\title{
Editorial
}

\section{La investigación en enfermería}

El conocimiento científico dentro del ámbito de la salud viene siendo relacionado con profesionales a los que clásicamente se les ha reconocido la capacidad investigadora (médicos, biólogos, químicos, etc.). Otros estamentos, como es el nuestro, no han desempeñado las tareas de investigación; han quedado relegadas a emplear el conocimiento científico construido por otros profesionales, y cuando no, a tomar decisiones ante situaciones sobre las que no hay estudios serios que orienten en la dirección adecuada. Es esta dejación de la función de investigar, la que ha jugado un papel decisivo en el hecho de que, hasta hace relativamente poco, las Escuelas Universitarias de Enfermería no hayan dado formación al respecto.

De cualquier forma, los enfermeros necesitamos investigar, según la OMS, "la Enfermería debe investigar para contribuir a que la población alcance estilos de vida saludables y una atención adecuada" y es responsabilidad nuestra, procurar los conocimientos necesarios para poder hacerlo.

Lo que desde la SEDEN nos gustaría dejar claro es que la investigación científica no es patente de ningún estamento profesional. Según el FIS, (Fondo de investigaciones Sanitarias de la Seguridad Social) "la investigación científica no es una actividad de élite ni un lujo, sino una necesidad".

Un trabajo de investigación no tiene por qué ser multidisciplinar, costoso y complejo, sino que puede analizarse cualquier pequeño detalle de nuestra labor diaria, y no por ello ser menos científico.

Por supuesto que nos encontramos obstáculos tales como que la actividad asistencial es muy absorbente, que no estamos lo suficientemente formados para investigar, que no estamos concienciados sobre la necesidad de investigar,....Pero todo esto tiene que cambiar. La investigación en Enfermería se dirige hacia un gran desarrollo, que poco a poco se va poniendo de manifiesto, como por ejemplo, en publicaciones y congresos.

La investigación, es una necesidad, es un deber de todo profesional el reflexionar sobre la realidad en la que actúa, obtener conocimiento y aplicarlo. Es por ello, por lo que hay que insistir en la utilidad de los estudios sobre investigación en enfermería, para mejorar los servicios de salud, y poder diferenciar el que los planes de cuidados de enfermería son más sólidos si los basamos en la evidencia y no en la experiencia intuitiva.

Desde aquí, os animamos a los que investigáis a que sigáis investigando, y a los que no habéis empezado, que poco a poco lo vayáis haciendo.

Alicia Gómez Gómez

Presidenta SEDEN 